\title{
ZU FRÜH- UND MITTELBRONZEZEITLICHEN FUNDEN VON BAJČ IN DER SÜDWESTSLOWAKEI
}

\author{
Zoja Benkovsky-Pivovarová
}

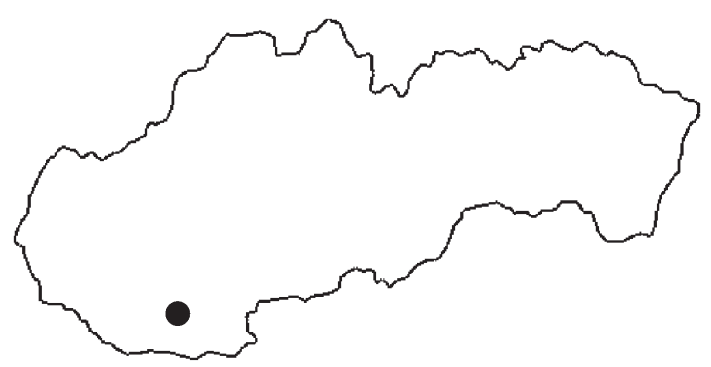

DOI: https://doi.org/10.31577/szausav.2019.66.1

Keywords: Southwestern Slovakia, Early Bronze Age, Únětice culture, female graves with daggers, Middle Bronze Age, Mad'arovce Culture, Füzesabony-Ottomani cultural complex, stone amulets, pithoi, Penetration of Middle Danube culture to the East

Early and Middle Bronze Age finds from Bajč in Southwestern Slovakia

Three graves with daggers were uncovered at the burial ground in Bajč-Ragoňa II in 1964. In one of them, in grave 39, 50-60 year-old woman was buried. The list of positively anthropologically comfirmed and probably female graves with daggers of the Únětice culture in Moravia and Slovakia, including grave 100 of the Mad'arovce culture from Jelšovce, proves that daggers approx. 5-18 cm long come from graves of 20-60 year-old women.

Besides others, finds from the Middle Bronze Age were discovered at the settlement in Bajč-Vlkanovo during the research in 1964 and 1965. It is questionable whether the bronze artifacts from feature IX can be characterized as a hoard. A stone amulet and a vessel sherd resembling pottery from the so-called A2/B1 transitive horizon from this feature are noteworthy. A large vessel of the Middle Danube Tumulus culture comes from pit 13. It was probably used as a pithos; seven graves of this type are known from the Early and Middle Bronze Age in Slovakia. Pottery of the Middle Danube Tumulus culture was also discovered in pit 27; pit 56 contained pottery of the Mad'arovce culutre and the Otomani-Füzesabony cultural complex. In general, finds from this settlement document slow penetration of the Middle Danube Tumulus culture in the environment of surviving Early Bronze cultures of the Northwestern Carpathian basin in stage B1.

Dieser Beitrag befasst sich mit drei Gräbern mit Dolchen im Gräberfeld in der Flur Ragoňa II und mit Siedlungsfunden in der Flur Vlkanovo in Bajč, die das AISAW in den Jahren 1959-1960 (Vlkanovo) und im Jahre 1967 (Ragoňa II) freilegte. Sie wurden zwar in den sechziger und siebziger Jahren des 20. Jh. veröffentlicht, verdienen aber etwas mehr Aufmerksamkeit. Die Fundstelle Šurany-Nitriansky Hrádok (vormals Nitriansky Hrádok) wird untenstehend unter Nitriansky Hrádok zitiert.

\section{ZU GR ÄBERN MIT DOLCHEN VON BAJČ-RAGOŇA II}

Im Jahre 1973 erschien eine eingehende Analyse der anthropologischen Funde aus dem Gräberfeld in der angegebenen Flur von H. Hanáková und M. Stloukal, die auch knappe, von A. Točík verfasste Angaben zum Befund und Inventar der Gräber enthielt (Hanáková/Stloukal/Točík 1973). Im Jahre 1979 wurde dieses Gräberfeld - leider ohne demographische Daten - von A. Točík im Korpus der südwestslowakischen frühbronzezeitlichen Gräberfelder veröffentlicht (Točík 1979, 238 ff.).

Das Inventar des sekundär gestörten Grabes 58 setzte sich nach A. Točík aus einem Dolch, einer Scheibenkopfnadel, dem Oberteil einer Hülsenkopfnadel und je einem Fragment eines Spiralröhrchens und eines kantigen Drahts zusammen (Točík 1979, 257, Abb. 184; Taf. XXXII: 6; XCVIII: 14, 15). Nach M. Novotná (1980, Nr. 46) war aber in diesem Grab an Nadeln nur eine damals noch unpublizierte Hülsenkopfnadel vorhanden, was sich bei der Durchsicht der Funde als richtig erwies; sie hat einen Hülsenkopf mit röhrchenförmig gestaltetem Oberteil, einen gebogenen Schaft und ist $10 \mathrm{~cm}$ lang (Abb. 1: 1). Den Dolch ordnete J. Vladár der Variante Nesvady der Dolche vom Typ Hurbanovo zu; er nahm ihn offenbar noch vor der Reinigung auf (Vladár 1974, Nr. 75), da in der Gegenwart außer den drei (ursprünglich vier) ausgebrochenen Nietlöchern auch der halbkreisförmige Schaftausschnitt sowie der flache spitzo- 
vale Querschnitt erkennbar sind und die Länge des Dolches nur noch 8,2 cm beträgt (Abb. 1: 2). Der Dolch repräsentiert den Dolchtyp N2.1 nach M. Bartelheim (1998, Taf. 44: N2.1), verlässliche Analogien der Nadel stammen aus dem Grab 5 von Matúškovo und dem Grab von Vinodol (Benkovsky-Pivovarová/Chropovský 2015a, Taf. 31: 5: 8; Točík 1979, Taf. LXVI: 6; LXXVIII: 1). Im Grab 58 war ein Mann im Alter von 30-40 Jahren bestattet (Hanáková/Stloukal/Točík 1973, 66).

Im Gräberfeld von Bajč gab es auch noch ein zweites Grab (Grab 39) mit Hülsenkopfnadel und Dolch, in welchem aber eine 50-60-jährige Frau beigesetzt war (Hanáková/Stloukal/Točík 1973, 65). Diese Hülsenkopfnadel hat ebenfalls einen röhrchenförmigen Kopfoberteil, aber ihr Schaft ist tordiert und beim Dolch handelt es sich um ein dreinietiges Exemplar mit einer Länge von nur 4,6 cm, außerdem fand sich hier Drahtschmuck (Novotná 1980, Nr. 47; Točík 1979, 251, Taf. XCVI: 20-24). Obwohl sich in diesem ebenfalls gestörten Grab zwei Schädel fanden, von denen einer offenbar nicht für anthropologische Untersuchungen zur Verfügung stand (Točík 1979, Abb. 178), kann dieses Grabinventar durchaus mit der weiblichen Bestatteten im $\mathrm{Zu}-$ sammenhang gebracht werden, und zwar angesichts einer ähnlichen Situation im Grab 110 von Jelšovce. Dieses sekundär ungestörte Grab 110 einer Frau im Maturus-Alter enthielt nämlich an Bronzegegenständen u. a. einen Dolch, einen Pfriem und eine Nadel; in diesem Falle war es ein größerer ritzverzierter Dolch und eine Kugelkopfnadel (Bátora 2000, 69 f., Taf. 10-110: 20, 23, 24).

Angesichts des überaus reichen Bronze- und Goldinventars des Grabes 26 - des dritten Grabes mit Dolch von Bajč - ist die nicht eindeutige Geschlechtsbestimmung des Toten, der als ein „unsicherer" Mann im Alter von 20-30 J. bestimmt wurde, sehr bedauerlich (Hanáková/Stloukal/Točík 1973, 63 f., Angaben zu diesem Grab wurden irrtümlich an das Grab 25 angeschlossen). Deswegen sei nur darauf hingewiesen, dass der Dolch in diesem Grab 12,2 cm lang ist (Točík 1979, 246, Abb. 173; Taf. XCV: 21).

Das Vorhandensein eines Dolches im Frauengrab 39 von Bajč ist an sich wenig überraschend; in der Aunjetitz-Kultur Mährens waren Dolche in einigen anthropologisch nachgewiesenen Frauengräbern vorhanden. Zu nennen sind zwei Gräber von Rebešovice, ein Grab von Těšetice-Vinohrady, ein Grab von Mušov und ein „unsicheres“ Frauengrab von Slavkov u Brna (s. Liste unten). Im in der Literatur in diesem Zusammenhang oft zitierten Grab 11 von Velký Grob I wurden Skelettreste von zwei Toten gefunden, von denen der eine als ein vermutlicher Mann und der andere als ein juveniler Mann bestimmt wurden; diese Geschlechtsbestimmungen stimmen allerdings nicht mit der Deutung des Grabes durch den Ausgräber und der „weiblichen“ Lage, Orientierung und der reichen Schmuckausstattung überein, deswegen sei nur erwähnt, dass der Dolch aus diesem Grab 4,1 cm lang ist (Benkovsky-Pivovarová/Chropovský 2015a, 131 f., Taf. 87-11: 7; Chropovský 1960, 21, 100). Das Grab 272 von Branč, dessen Inventar aus einer Nadel, einem Dolch, einem Pfriem und Drahtschmuck bestand, wurde in der Monographie des Gräberfeldes als ein Frauengrab bezeichnet (Vladár 1973, 110 f., Taf. XXXVII: 272), leider aber blieben die Resultate der anthropologischen Untersuchungen unveröffentlicht (Furmánek 1997, 76 f.); der Dolch aus diesem Grab ist $13 \mathrm{~cm}$ lang (Vladár 1973, 111, Taf. XXXVII: 2).

In der unten stehenden Liste sind die der Verfasserin bekannten anthropologisch nachgewiesenen sicheren und vermutlichen Frauengräber mit Dolchen in der Aunjetitz-Kultur Mährens und der Slowakei inklusive des Grabes 110 der Madarovce-Kultur von Jelšovce zusammengestellt. 
1. Bajč, Grab 39: Frau, maturus, 50-60 J.; Dolchlänge 4,6 cm (Hanáková/Stloukal/Točík 1973, 65; Točík 1979, Abb. 178; Taf. XCVI: 22).

2. Jelšovce, Grab 110: Frau, maturus II; Dolchlänge 9,95 cm (Bátora 2000, 70, 398, Taf. 10-110: 20, 21).

3. Mušov, Grab 26: Frau, $40-50$ J.; Dolchlänge 6,9 cm (Stloukal 1987, 102; Stuchlík 1987, 18 f., Abb. 27: 19).

4. Rebešovice, Grab 8: Frau, 20-25 J.; Dolchlänge 6,1 cm (Ondráček 1962, 8, Abb. 40: 12).

5. Rebešovice, Grab 129: Frau, e. 20 J. + Kind; Dolchlänge e. $18 \mathrm{~cm}$ (Dolch aus dem Grab entnommen, L. nach Abdruck im gestörten Teil der Grabgrube vor der Brust der Frau: Ondráček 1962, 18, Abb. 47: 1, 2).

6. Slavkov, Grab 9: verm. Frau, adult; Dolchlänge e. 5 cm (Dočkalová-Svenssonová 2000, 38; HorálkováEnderová/Štrof 2000, 23, Taf. 12: 4).

7. Tešetice-Vinohrady, Grab 22: Frau, 20-24 J.; Dolchlänge 5,8 cm (Lorencová/Beneš/Podborský 1987, 45, 154, Abb. 14b: 3).

Aus dieser Liste ergibt sich, dass die Dolche in den Frauengräbern der Aunjetitz-Kultur in Mähren und der Slowakei etwa 5-18 cm lang waren und Frauen im Alter von 20-60 J. beigegeben wurden. Für Untersuchungen der typologischen und eventuell auch funktionsmäßigen Unterschiede der Dolche in den Männer-, Frauen- und Kindergräbern in der mährisch-niederösterreichischen und der slowakischen Gruppe der Aunjetitz-Kultur wäre eine größere Anzahl der Gräber mit sicheren anthropologischen Daten notwendig.

\section{ZU SIEDLUNGSFUNDEN VON BAJČ-VLKANOVO}

In der Siedlung von Bajč-Vlkanovo kamen während der Grabung des AI SAW in den Jahren 1964 und 1965 außer neolithischer, äneolithischer, urnenfelder-, hallstatt- und latènezeitlicher sowie frühmittelalterlicher Funde auch Funde der mittleren Bronzezeit zum Vorschein, die A. Točík in die Stufe B1 datierte und sie der Anfangsphase der Karpatenländischen Hügelgräberkultur zuordnete (Objekt IX und die Gruben 27 und 56: Točík 1964b, 13, 166). Auf die Funde aus der Grabung am Anfang der achtziger Jahre auf derselben Fundstelle kann nicht eingegangen werden, da O. Oždáni im Jahre 2010 gemäß der Fragestellung nur eine Auswahl der Funde fremder Provenienz aus dem Objekt 39/82 veröffentlichte; der Großteil der Funde aus dieser Grube gehört seiner Angaben nach der späten Mad’arovce-Kultur an (Ožd’áni 2010, 260, Taf. I).

Zuerst sei auf die Funde aus dem Objekt IX eingegangen. In der stellenweise aschigen Verfüllung einer unregelmäßig kreisförmigen, $116 \mathrm{~cm}$ tiefen Grube mit einem Durchmesser von $235 \mathrm{~cm}$ fanden sich Hüttenlehmfragmente, Tierknochen, zwei teilweise erhaltene Krüge (Abb. 2: 7, 9), Scherben mehrerer Gefäße, eine Spinnwirtel, ein als ein mögliches Idol interpretierter Steingegenstand (Abb. 2: 8) und Bronzegegenstände zwei Sichelnadeln, ein Scheibenanhänger, ein Ring mit Spiralscheiben und ein Tüllenmeißel (Abb. 2: 1-5). Dieses Objekt wurde als eine Lehmentnahmegrube interpretiert, die sekundär als Abfallgrube verwendet wurde und in der ein Depot von Bronzegegenständen deponiert war (Toč́k 1964b, 13, 79 f., Abb. 86). Ob es sich allerdings um einen Depotfund handelte, ist fraglich, da aus dem Befund nicht hervorgeht, dass die Bronzegegenstände in der geräumigen Grube beisammen angetroffen wurden. Der Tüllenmeißel (Abb. 2: 5) repräsentiert einen charakteristischen Meißeltyp der beginnenden mittleren Bronzezeit (Hänsel 1968, 72), der in der Slowakei im kosziderzeitlichen Depotfund von Kamenín enthalten ist (Janšák 1938, Taf. 6: 10; Mozsolics 1967, 143; Novotná 1970, 69 f., Nr. 434, 443); der Tüllenmeißel von Bajč könnte also durchaus für eine Deutung der Bronzefunde im Objekt IX als Depot sprechen. Die restlichen Bronzefunde aus diesem Objekt - zwei Sichelnadeln, ein Scheibenanhänger und ein Ring mit Spiralscheiben machen hingegen den Eindruck des Inventars eines Frauengrabes (Abb. 2: 1-4). Mit der Vergesellschaftung von Sichelnadeln mit Scheibenanhängern befasste sich eingehend W. David (1998, 317 ff.), hier seien nur die Inventare der Gräber 24 von Svätý Peter (vormals Dolný Peter), der Gräber 919 und 1060 von Ménfőcsanak sowie des Grabes 854a von Dunaújváros genannt, in denen Sichelnadeln mit zwei- bis dreirippigen Scheibenanhängern vergesellschaftet waren (Dušek 1969, Abb. 11: 3-6; 12: 1-10; Egry 2004, Abb. 3: 3-8; 6: 1, 2, 4; Vicze 2011, Taf. 216-854a: 3, 4). Fingerringe mit Spiralscheiben (Abb. 2: 3) fanden sich in Begleitung von Sichelnadeln in den Gräbern 11 und 27 von Svätý Peter (Dušek 1969, Abb. 7: 1-3; 13: 1-4, 20, 21). Möglicherweise trüge eine Analyse der Knochenfunde aus diesem Objekt zur Klärung dieser Frage bei.

Eine verlässliche Bewertung der kulturellen Zugehörigkeit der Keramik aus dem Objekt IX ist angesichts der oftmals fehlenden Profilzeichnungen der Scherben nicht immer möglich. Die beiden teilweise erhaltenen Krüge gehören zweifelsohne der Madarovce-Kultur an (Abb. 2: 7, 9), wobei der Krug mit 


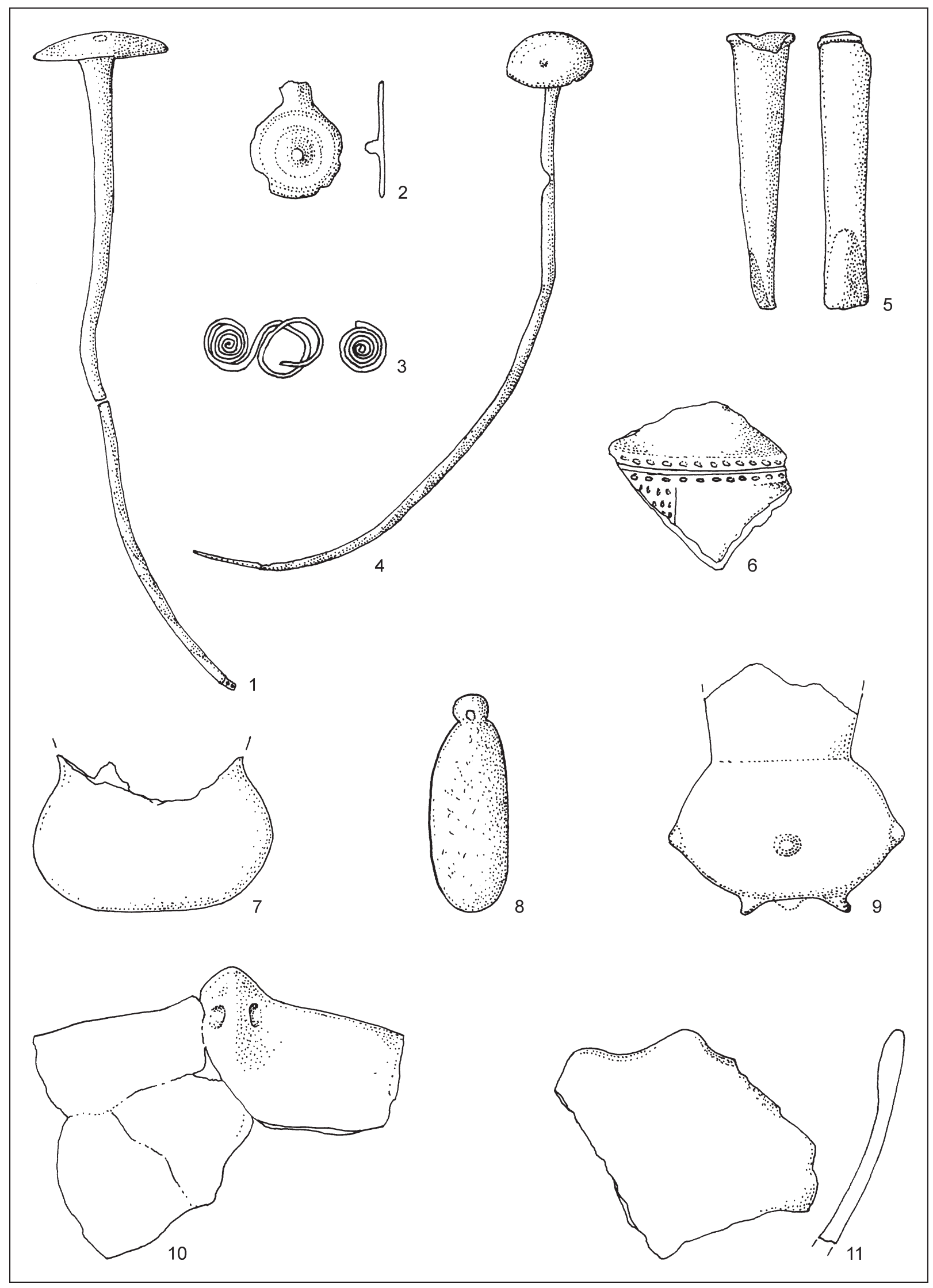

Abb. 2. Bajč-Vlkanovo. Funde aus dem Siedlungsobjekt IX, Auswahl (nach Točík 1964b). Ohne Maßstab. 
Buckelverzierung den erwähnten Eindruck des Inventars eines Frauengrabes im Objekt IX noch verstärkt. Mit der chronologischen Stellung der Krüge mit derartiger Verzierung befasste ich mich andernorts (Benkovsky-Pivovarová 2004; 2016, 21), es wäre aber noch zum Krug aus dem Objekt 10/84 von Štúrovo in seiner Funktion als Grabbeigabe Stellung zu nehmen. Hier waren in einer Grube, die Tierknochen und ein reichliches Keramikgut enthielt, zwei Kinder im Alter Infans III bestattet, und zwar einer der Toten am westlichen Grubenrand in strenger linker Hockerlage mit Orientierung etwa SSO - NNW und der andere im Ostteil der Grabgrube in lockerer rechter Hockerlage mit Orientierung etwa NNV - SSO (Ožd'áni 2010, Taf. III-VI). Zur Lage und dem Geschlecht der beiden Toten gibt es unterschiedliche Interpretationen; von P. Jelínek wurde im Jahre 2007 unter Berufung auf eine Information seitens O. Oždáni der Tote in strenger Hockerlage als Junge, der andere als Mädchen bezeichnet (Jelínek 2007, 77), aber nach neueren Angaben handelte es sich beim Toten in rechter Hockerlage um einen 8-9-jährigen Jungen und bei der Toten in linker Hockerlage um ein 9-10-jähriges Mädchen (Jelínek 2016, 29), was als Fortführung der geschlechtsspezifischen Bestattungsart in der frühen Bronzezeit plausibler erscheint (z. B. Furmánek/ Veliačik/Vladár 1991, 283). Während bei dem Jungen als Grabinventar die Spitze eines Hirschgeweihs und ein Amulett aus Fischgrat angeführt werden (Jelínek 2016, 29), fehlen derartige Hinweise bei dem Mädchen, jedoch ist aus dem veröffentlichten Plan klar zu ersehen, dass bei den Füßen des in strenger linker Hockerlage bestatteten Mädchens ein Krug mit Buckelverzierung stehend deponiert wurde (Ožd'áni 2010, Taf. III links). Eine solche gendermäßige Bewertung dieser Keramikbeigabe wird durch das Grab 1060 von Ménfőcsanak unterstützt, wo sich der Krug mit Buckelverzierung in Kopfnähe einer juvenilen, auf linker Seite bestatteten Frau fand (Egry 2004, 130, Abb. 6). Es können daher nicht alle zum Teil fragmentierten und in der Grube von Štúrovo verstreuten Gefäße als Beigaben der Doppelbestattung interpretiert werden (Jelinek 2016, 29; Ožd’áni 1985, 183).

Die Schüsseln mit senkrechter Öse (Abb. 2: 10) knüpfen an die Schüsseln der Mad’arovce-Kultur vom Typ D1b nach A. Točík an (1981b, Beilage 3, Taf. LXX: 18; CXXIII: 1; CXXVI: 21 u. w.). Hingegen gehört das Fragment einer konischen Schüssel mit Randlappen der Mitteldonauländischen Hügelgräberkultur an (Abb. 2: 11); auf derartige Schüsseln wird noch zurückzukommen sein. Eine Hals/Wand-Scherbe mit Doppelstichverzierung (Abb. 2: 6) erinnert an die Keramik des sog. Übergangshorizontes bzw. Vorhügelgräberhorizontes in Oberösterreich, Bayern und Böhmen, allerdings ist aus der Zeichnung nicht klar zu ersehen, ob es sich um die Verzierung einer Leiste handelt. Einwandfrei können mit dem erwähnten Horizont zwei Scherben mit halbkreisförmigen Stempeleindrücken aus der kosziderzeitlichen Siedlung von Mannersdorf am Leithagebirge in Verbindung gebracht werden (Neugebauer 1981, 173, Abb. 10: 29; 23: 95). Im chronologischen Einklang mit den erwähnten Gefäßfragmenten von Bajč und Mannersdorf ist das Vorkommen von Scherben eines Gefäßes mit einer solchen Verzierung im B1-zeitlichen Hügelgrab 75 von Plzeň-Nová Hospoda (Čujanová-Jílková 1970, Taf. 88A). Auf Beziehungen zum genannten Horizont wies S. Stuchlík bei der Auswertung der Siedlungskeramik der Stufe B1 von Křižanovice hin (Stuchlík 1971, 144; s. auch 1992, Abb. 21: 3).

Bei dem als vermutliches Idol interpretierten, 1t. Beschreibung flachen Steingegenstand (Abb. 2: 8) handelt es sich aller Wahrscheinlichkeit nach um ein Amulett. Auf die Steinamulette in der Vatya-, Szöreg-, Varsand (Gyulavársánd)-, Füzesabony- und Vatin (Vattina)-Gruppe machte I. Bóna aufmerksam; im Grab 17 von Ószentiván ist die Funktion eines Steinamulettes als Halsschmuck nachgewiesen (Bóna 1975, 103, 137, 162, 186). Die Steinamulette haben unterschiedliche Form und sind mit Lochung, umlaufenden Rillen bzw. Spalten oder mit seitigen Einkerbungen versehen (Banner 1928, Abb. 72; 1929, Abb. 4: 1; Bóna 1975, Taf. 150: 4, 5; Milleker 1905, Taf. IV: 1-4; Popescu 1944, Abb. 24: 16; 1956, Abb. 77: 4; Taf. 4: 1-4; Tompa 1937, Taf. 42: 23, 24). Aus der Slowakei sind der Verfasserin drei Steinamulette bekannt. Ein vierkantiges Amulett aus Sandstein mit einer umlaufenden Rille im abgerundeten Oberteil, 4,6 cm lang, fand sich in der Tiefe 0-60 cm (obere Schicht und kelto-dakische Schicht) im Sektor 0/22 von Nitriansky Hrádok in der Südwestslowakei (Toč́k 1981a, 187, Taf. CLXXXIII: 13); ein etwas größeres Amulett des gleichen Typs - ein Einzelfund - stammt aus Humenné in der Ostslowakei (Vizdal 1986, 239, Abb. 114: 2). Ein Anhänger aus flachem Stein mit ovalem Loch kam in der Tiefe 140-170 cm (oberer Madarovce-Siedlungshorizont) im Sektor D/24 in Nitriansky Hrádok zum Vorschein (Točík 1981a, 44; ohne Abbildung). Es kann angenommen werden, dass die Anzahl der in der Südwestslowakei vorhandenen Steinamulette ansteigen wird, wenn man ihnen mehr Aufmerksamkeit schenkt. So wurden z. B. die Steinerzeugnisse von Nitriansky Hrádok meistens mit unzureichender Beschreibung und ohne Abbildung veröffentlicht, deswegen kann bei den mit einer Einschnürung, einer Rille oder einem Loch versehenen Exemplaren bzw. ihren Fragmenten nicht immer mit ausreichender Sicherheit zwischen den Armschutzplatten, Schleifsteinen und Amuletten unterschieden werden (s. z. B. Točík 1981a, 256, Taf. CIX: 25). 


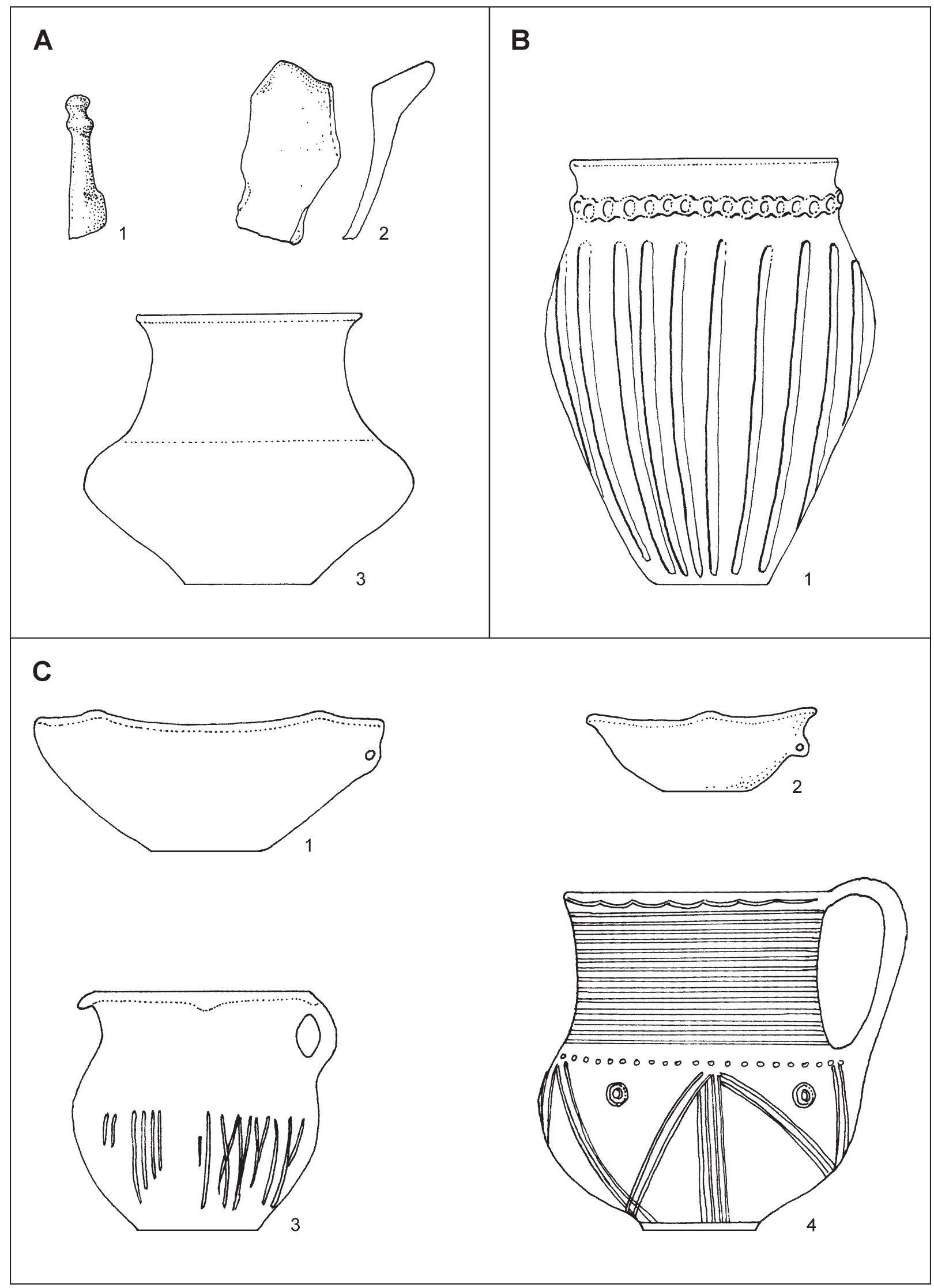

Abb. 3. Bajč-Vlkanovo. Funde aus den Gruben 13, 27 und 56, Auswahl (nach Toč́́k 1964b). Ohne Maßstab. 
Die Amulette von Nitriansky Hrádok (Nr. 5) und Humenné (Nr. 4) sind vom gleichen Typ wie einer der Amulette von Varsand (Gyulavársánd; Bóna 1975, Taf. 150: 5), deswegen könnten sie vielleicht auf den Einfluss des Füzesabony/Otomani-Kulturkomplexes zurückgeführt werden, allerdings stammen von der Fundstelle in Humenné nach wie vor nur Funde der Bükker Kultur (Vizdal 1986, 239; frdl. Mitteilung von I. Strakošová vom August 2018). Zum Amulett von Bajč (Nr. 1) sind mir keine Analogien bekannt.

Unmittelbar an das Objekt IX in Bajč grenzte die Grube 56 (Toč́́k 1964b, Abb. 2), die einen Krug mit doppelkonischem Unterteil, eine Randscherbe einer Schüssel mit gelapptem Rand (Abb. 3: A: 2, 3), eine Randscherbe und eine Wandscherbe zweier Gefäße und Fragment einer Nadel mit profiliertem Kopf und senkrechter Öse enthielt (Abb. 3: A: 1; Toč́́k 1964b, 53 f.). Der Krug (Abb. 3: A: 3) stellt eine charakteristische Form der Mitteldonauländischen Hügelgräberkultur in der Westslowakei, in Mähren, Mittelböhmen und dem nördlichen Niederösterreich dar, die aus Siedlungen, Gräbern und Depotfunden bekannt ist (Bartík 1996, Taf. 2: 1; Neugebauer/Blesl 1998, Abb. 19: 1-9; Řihovský 1982, Taf. 20A: 2). Den Unterschied in der Formgebung sieht man sehr deutlich beim Vergleich des Kruges von Bajč mit Krügen im größten Gräberfeld der Karpatenländischen Hügelgräberkultur von Salka I; ein hochhalsiger Krug fand sich nur in einem von insgesamt 172 Gräbern (Grab 85: Toč́k 1964a, Taf. XVIII: 7) und ist daher als Importware zu werten. Das Fragment einer konischen Schüssel mit Randlappen aus der Grube 55 steht mit der kulturellen Zuordnung des Kruges im Einklang; es repräsentiert die Schüsseln vom Typ D2 der Mitteldonauländischen Hügelgräberkultur nach J. Bartík (1996, 208, Abb. 3). Da sich das Auftreten des Kruges und der Schüssel im Rahmen der mittleren Bronzezeit chronologisch nicht einschränken lässt, sei auf das Vorhandensein der Schüssel mit Randlappen im bronzedatierten Grab der Stufe B1 von Sudoměřice und in der Grube 2 von Křižanovice hingewiesen (Stuchlík 1992, Abb. 20: 3; 21: 6, 8, 17). Auch der Oberteil einer Nadel trägt zur Datierung der Grube 55 von Branč nur bedingt bei. Angesichts der B1-zeitlichen Nadel mit langer senkrechter Öse und profiliertem Schaft von Amberg-Kleinragering (Innerhofer 2000, Taf. 3: 5; Torbrügge 1959, 105, Taf. 3: 9) kann ein derartig gestalteter Unterteil auch bei der Nadel von Bajč und damit die Datierung der Grube 56 in die erwähnte Stufe nicht ausgeschlossen werden.

Während das Objekt IX und die Grube 56 im Westteil der aufgedeckten Fläche der Siedlung zum Vorschein kamen, befand sich die Grube 27 etwa $32 \mathrm{~m}$ südöstlich davon, allerdings wurde die dazwischen liegende Fläche nicht freigelegt (Točík 1964b, Abb. 2). In dieser Grube fand sich ein Krug, ein Töpfchen, zwei Schüsseln (Abb. 3: C: 1-4), Scherben weiterer nicht abgebildeter Gefäße und Tierknochen (Točík 1964b, 36 f.). Der reich verzierte Krug (Abb. 3: C: 4) gehört dem Füzesabony/Otomani-Kulturkomplex an; er wurde bei der Kartierung des Vorstoßes dieses Kulturkomplexes in westlicher Richtung berücksichtigt (Benkovsky-Pivovarová 1998, Abb. 3). Aufgrund der Verzierungsart kann er mit mehreren Krügen vom Gräberfeld in Streda nad Bodrogom und von der Siedlung II in Nižná Myšla verglichen werden (Olexa 1992, Taf. I: 9; 2003, Taf. X: 5; Polla 1960, Taf. V: 3; VIII: 5; XI: 4; XIII: 4; XIV: 4 u. w.). Mit Krügen dieses Typs von Streda nad Bodrogom und ihrer Weiterentwicklung befasste sich ausführlich B. Hänsel; er datierte sie in die Stufen MD II und MD III (Variante 4: Hänsel 1968, 145 ff.). Die Siedlung II von Nižná Myšla wird von L. Olexa der nachklassischen Phase der Füzesabony/Otomani-Kultur zugeordnet, in die Stufe B1 datiert und mit dem Gräberfeld von Streda nad Bodrogom parallelisiert (Olexa 1983, 128; 1992, 194). Die Schüsseln aus der Grube 27 von Bajč (Abb. 3: C: 1, 2) betrachtete A. Točík als ein Erbe der MadarovceKultur, das Töpfchen mit gelapptem Mundsaum und gerauhter Wandung (Abb. 3: B: 3) als ein gemeinsames Erbe der frühbronzezeitlichen Kulturen Transdanubiens und des Theißgebietes (Točík 1964b, 13). Die Schüsseln repräsentieren den Typ B1a und B1b der Madarovce-Kultur des Autors, für das Töpfchen sind vergleichbare Formen in den Siedlungen von Nitriansky Hrádok und Malé Kosihy zu finden (Točík 1981b, Beilage 3, Taf. CXIV: 10; 1981a, Abb. 16: 4).

Im Katalogteil der Publikation von Bajč wird auch noch die Grube 13 in die mittlere Bronzezeit datiert, mit der sich A. Točík in der Auswertung der mittelbronzezeitlichen Fundkomplexe von der Fundstelle nicht befasste. Sie enthielt $u$. a. Tierknochen und Scherben von sieben Gefäßen, von denen aber von sechs Gefäßen jeweils nur eine Scherbe vorliegt (Točík 1964b, 28, Taf. XVII: 2-6, 8; Divergenzen zwischen Angaben im Text und auf der Tafel); eine von ihnen wurde als bronze- oder hallstattzeitlich angesprochen (Nr. 1). Bemerkenswert ist vor allem ein zusammensetzbarer, $42 \mathrm{~cm}$ hoher, S-förmig profilierter Topf mit einer Grübchenleiste am Halsansatz und senkrechter Rillenverzierung des Körpers (Abb. 3: B). Auf den Scherben dieses Gefäßes lagen 1t. Befund winzige Knochen vermutlich eines Kindes und Asche. Das Gefäß kann bei aller Vorsicht mit der mitteldonauländischen Hügelgräberkultur in Verbindung gebracht werden. Für diese Kultur sind Töpfe bzw. Vorratsgefäße mit waagrechter Grübchenleiste und senkrechter Rauhung des Körpers kennzeichnend (z. B. Bartík 1996, Vorratsgefäße, Typ 1D; Bartík/Elschek/Varsik 2013, Taf. 33: 3; Dušek 1980, Taf. III: 18; XI: 10; Stuchlík 1993, Abb. 175: 23), aber die Verzierung des Gefäßkörpers mit 
tiefen, weit auseinander liegenden Rillen ist bei den Töpfen mit Grübchenleiste ungewöhnlich; es fragt sich, ob die Zeichnung diesbezüglich den Tatsachen entspricht. Die Töpfe mit Grübchenleiste der gennanten Kultur sind meistens senkrecht gerauht; der tiefen Rillenverzierung begegnet man eher bei anderen Gefäßtypen (z. B. Říhovský 1982, Taf. 1: D: 1; 3: B: 4; 5: C: 1; 13: B: 3 u. v. w.). Nicht nur die archäologischen, sondern auch die anthropologischen und osteologischen Funde aus dieser Grube würden eine Neuvorlage verdienen; es ist sehr wahrscheinlich, dass der Topf als Pithos diente. In Unkenntnis seiner Begleitfunde ist keine Stellungnahme zu seiner näheren Datierung möglich, aber als Pithos-Grab der Mitteldonauländischen Hügelgräberkultur stünde er keinesfalls als eine Ausnahmeerscheinung da; in Olšany bei Prostějov wurde ein amphorenartiges Gefäß, das ein komplettes Kinderskelett enthielt und mit dem Unterteil eines großen Gefäßes abgedeckt war, in eine in die mittlere Phase der Mitteldonauländischen Hügelgräberkultur datierte Siedlungsgrube eingetieft (Fojtík/Dočkalová 2007, 61, Abb. 3; Stuchlík 2007, 202).

In der untenstehenden Liste konnte das Pithosgrab von Šarovce nicht berücksichtigt werden, da es in der Literatur ohne Quellennachweis zitiert wird (Furmánek/Veliačik/Vladár 1991, 285). Aus der Südwestslowakei sind bis dato folgende Pithosgräber bekannt:

1. Bajč: Winzige Knochen vermutlich eines Kindes, ursprünglich im Topf deponiert; mitteldanubische Hügelgräberkultur (Točík 1964b, 28, Taf. XVII: 6).

2. Čachtice: Skelett in einem Großgefäß (beides nicht erhalten), zu Füßen Henkeltöpfchen; Mad’arovceKultur (Benkovsky-Pivovarová/Chropovský 2015a, 54, Taf. 25: B: 1; Kolník/Paulík 1959, 89, 96, Taf. I: 11).

3. Nitra, Objekt IV (Grab 4): Schädel und einige Knochen vermutlich eines Mädchens im Alter von 14-17 Jahren, ursprünglich im Topf deponiert; Karpatenländische Hügelgräberkultur (B̌rezinoválJakab/Vladár 2012, 27-35, Abb. 5: 1).

4. Nitriansky Hrádok, südlicher Schnitt aus 1951: Kinderskelett in einer Amphore vom Typ C-2c, mit einer Scherbe abgedeckt; Mad’arovce-Kultur (Knor 1952, 246, Abb. 125).

5. Nitriansky Hrádok, Sektor G/18: Kinderskelett in einer stehenden Amphore, mit einer Schüssel abgedeckt; Mad’arovce-Kultur (Toč́́k 1981b, 26 f., Plan 67: 2, Taf. CXXVI: 2, 3).

6. Nitriansky Hrádok, Sektor H/22: Kinderskelett in einem liegenden Topf, mit einer Schüssel abgedeckt; Madarovce-Kultur (Toč́́k 1981b, 74, Taf. CXXXVIII: 23, 24).

7. Patince, Grab in der Hütte IV: Kinderskelett und Schädelreste eines erwachsenen Individuums im Topf; Nordpannonische Kultur (Dušek 1960, 206 ff., Abb. 12; Taf. XLIX: 24).

In den Gefäßen wurden also meistens Kinder bestattet, wobei als Behälter Töpfe (Nr. 1, 6, 7) und Amphoren (Nr. 4, 5) dienten; in einem Fall fanden sich im Pithos auch noch Schädelfragmente eines/r Erwachsenen (Nr. 7). In einem Topf wurde auch ein Mädchen beigesetzt (Nr. 3), über den in einem Topf bestatteten Toten ist nichts bekannt (Nr. 2). In drei Fällen wurde der Pithos mit einer Scherbe oder einer Schüssel abgedeckt (Nr. 4-6); eine Gefäßbeigabe, ein Krug, war nur in einem Falle vorhanden (Nr. 2).

Obwohl an der Zahl gering, bezeugen das Objekt IX und die Gruben 27 und 56 von Bajč einmal mehr die komplizierte Situation im Gebiet zwischen Waag und Eipel am Beginn der mittleren Bronzezeit. Mit dem breit gefächerten kulturellen Bild der Keramik im Gräberfeld von Svätý Peter befasste ich mich im Jahre 1994 (Benkovsky-Pivovarová 1994), hier sei nur noch eine Charakteristik dieses Gräberfeldes durch I. Bóna zitiert: „Die Bronzefunde dieses Gräberfeldes (Armbänder, Sichelnadeln und Anhänger der Koszider-Epoche) sind noch einheitlicher, als die Töpferei. Bei den Gefäßen herrscht großes Chaos, denn hier haben sich Produkte aller Himmelsrichtungen getroffen, wenn auch nicht ihre Hersteller" (Bóna 1992, 38). Allerdings ist in diesem Gebiet am Beginn der mittleren Bronzezeit nicht nur mit Einflüssen und Importen, sondern auch mit Invasionen zu rechnen. Die mächtigste von ihnen war wohl die der Vatya-Kultur, leider aber sind die Siedlungsfunde von Dvory nad Žitavou, Mužla-Čenkov und Štúrovo bis jetzt nur unzureichend bekannt.

Die kulturelle Vielfältigkeit der Siedlungsfunde von Bajč-Vlkanovo bezeugt die Nichtberechtigung ihrer eingangs erwähnten Einreihung in eine „Anfangsphase der Karpatenländischen Hügelgräberkultur“ durch A. Točík. Die einzigen Funde, die man hier mit der Hügelgräberkultur in Verbindung bringen kann, gehören der Mitteldonauländischen Hügelgräberkultur an, die am Beginn der mittleren Bronzezeit allmählich in das Milieu der während der Stufe B1 weiterlebenden frühbronzezeitlichen Kulturen im nordwestlichen Karpatenbecken vorstieß, was bis jetzt hauptsächlich durch Grabfunde fassbar war; darauf, dass der Vorstoß aus dem Westen besonders gut im Nitra-Tal zu beobachten ist, wies A. Točík bereits vor über 50 Jahren hin (Točík 1978, 73). Es bleibt zu hoffen, dass die Grab- und Siedlungsfunde dieser Stufe aus der Südslowakei bald veröffentlicht und sorgfältig untersucht werden. Daran ist die Erarbeitung eines neuen, die komplizierten kulturellen Verhältnisse in diesem Raum besser erfassenden Terminus gebunden. 


\section{LITERATUR}

Banner 1928

Banner 1929

Bartelheim 1998

Bartík 1996

Bartík/Elschek/Varsik 2013

Bátora 2000

Benkovsky-Pivovarová 1994

Benkovsky-Pivovarová 1998

Benkovsky-Pivovarová 2004

Benkovsky-Pivovarová 2016

Benkovsky-Pivovarová/Chropovský 2015a

Benkovsky-Pivovarová/Chropovský 2015 b

Bóna 1975

Bóna 1992

BřezinoválJakab/Vladár 2012

Čujanová-Jílková 1970

David 1998

Dočkalová-Svenssonová 2000

Dušek 1960

Dušek 1969

Dušek 1980

Egry 2004

Fojtík/Dočkalová 2007

Furmánek 1997
J. Banner: Az ószentiváni ásátások. Dolgozatok 4, 1928, 143-243.

J. Banner: Az ószentiváni bronzkori telep és temető. Dolgozatok 5, 1929, 52-81. M. Bartelheim: Studien zur böhmischen Aunjetitzer Kultur - Chronologische und chorologische Untersuchungen. Universitätsforschungen zur prähistorischen Archäologie 46. Bonn 1998.

J. Bartík: Sídlisko stredodunajskej mohylovej kultúry vo Veselom. Slovenská archeológia 44, 1996, 189-252.

J. Bartík/K. Elschek/V. Varsik: Praveké sídlisko v Lozorne-Širokých dieloch (západné Slovensko). Výskumy v rokoch 1999-2009. Zborník SNM. Archeológia. Supplementum 7. Bratislava 2013.

J. Bátora: Das Gräberfeld von Jelšovce/Slowakei. Ein Beitrag zur Frühbronzezeit im nordwestlichen Karpatenbecken. Prähistorische Archäologie in Südosteuropa 16, Kiel 2000.

Z. Benkovsky-Pivovarová: Zum bronzezeitlichen Gräberfeld von Dolný Peter in der Slowakei. Archaeologia Austriaca 78, 1994, 25-27.

Z. Benkovsky-Pivovarová: Zum Zeitpunkt des Vorstoßes der Otomani-Kultur in die Süd- und Westslowakei. In: M. Lamiová-Schmiedlová (ed.): Východoslovenský pravek V. Košice 1998, 33-38.

Z. Benkovsky-Pivovarová: K datovaniu krčiažka věteřovskej kultúry z Lednice (Eisgrub), okr. Břeclav. In: E. Kazdová/Z. Měřínský/K. Šabatová (ed.): K poctě Vladimíru Podborskému. Přátelé a žáci k sedmdesátým narozeninám. Brno 2004, 275-279.

Z. Benkovsky-Pivovarová: K terminológii počiatku strednej doby bronzovej na južnom Slovensku vo svetle nálezov z hrobu 3/62 mad’arovskej kultúry z Nových Zámkov. Zborník SNM 110. Archeológia 26, 2016, 19-26.

Z. Benkovsky-Pivovarová/B. Chropovský (ed.): Grabfunde der frühen und der beginnenden mittleren Bronzezeit in der Westslowakei 1. Archaeologica Slovaca Monographiae 21. Nitra 2015.

Z. Benkovsky-Pivovarová/B. Chropovský (ed.): Grabfunde der frühen und der beginnenden mittleren Bronzezeit in der Westslowakei 2. Archaeologica Slovaca Monographiae 22. Nitra 2015.

I. Bóna: Die mittlere Bronzezeit Ungarns und ihre südöstlichen Beziehungen. Archaeologia Hungarica. Series nova 49. Budapest 1975.

I. Bóna: Bronzezeitliche Tell-Kulturen in Ungarn. In: W. Maier-Arendt (Hrsg.): Bronzezeit in Ungarn. Forschungen in Tell-Siedlungen an Donau und Theiss. Frankfurt am Main 1992, 9-41.

G. Březinová/J. Jakab/J. Vladár: Fenomén - pohreby v nádobách. Ludské kosti v zásobnici karpatskej mohylovej kultúry v Nitre. Sborník Národního Muzea v Praze. Řada A. Historie 66/3, 4, 2012, 27-38.

E. Čujanová-Jílková: Mittelbronzezeitliche Hügelgräberfelder in Westböhmen. Archeologické studijní materiály 8. Praha 1970.

W. David: Zu Variantengliederung, Verbreitung und Datierung der kosziderzeitlichen Sichelnadeln. In: H. Ciugudean/F. Gogâltan (ed.): The Early and Middle Bronze Age in the Carpathian Basin. Proceedings of the International Symposium in Alba Iulia, 24-28 September 1997. Alba Iulia 1998, 281-370.

M. Dočkalová-Svenssonová: Pohřebiště a sídliště únětické kultury - antropologická zpráva. In: Horálková-Enderová/Štrof 2000, 36-52.

M. Dušek: Patince - pohrebisko severopanónskej kultúry. In: Chropovský/Dušek/Polla 1960, 219-344.

M. Dušek: Birituelles Gräberfeld der Karpatenländischen Hügelgräberkultur in Dolný Peter. In: M. Dušek (ed.): Bronzezeitliche Gräberfelder in der Südwestslowakei. Archaeologica Slovaca. Catalogi IV. Bratislava 1969, 50-81. M. Dušek, Pohrebisko ludu stredodunajskej mohylovej kultúry v Smoleniciach. Slovenská archeológia 28, 1980, 341-382.

I. Egry: Halomsíros temető Győr-Ménföcsanak-Bevásárlóközpont területén. MOMO $\Sigma$ III. Szombathely 2004, 121-137.

P. Fojtík/M. Dočkalová: Středobronzový pohřeb v nádobě z Olšan u Prostějova. Študijné zvesti AÚ SAV 42, 2007, 57-69.

V. Furmánek: Stand der demographischen Erforschung der Bronzezeit in der Slowakei. In: K.-F. Rittershofer (Hrsg.): Demographie der Bronzezeit. Paläodemographie. Möglichkeiten und Grenzen. Internationale Archäologie 36, 1997, 74-78. 
Furmánek/Veliačik/Vladár 1991 Hanáková/Stloukal/Točík 1973

Hänsel 1968

Horálková-Enderová/Štrof 2000

Chropovský 1960

Chropovský/Dušek/Polla 1960

Innerhofer 2000

Janšák 1938

Jelinek 2007

Jelínek 2016

Knor 1952

Kolník/Paulík 1959

Lorencová/Beneš/Podborský 1987

Milleker 1905

Mozsolics 1967

Neugebauer 1981

Neugebauer/Blesl 1998

Novotná 1970

Novotná 1980

Olexa 1983

Olexa 1992

Olexa 2003

Ondráček 1962

Ožd’áni 1985

Ožd’áni 2010

Polla 1960

Рореsсu 1944

Рореsси 1956

Říhovský 1982

Stloukal 1987
V. Furmánek/L. Veliačik/J. Vladár: Slovensko v dobe bronzovej. Bratislava 1991. H. Hanáková/M. Stloukal/A. Točík: Pohřebiště ze starší doby bronzové v Bajči. Časopis Národního muzea 142, 1973, 58-88, Taf. I-VIII.

B. Hänsel: Beiträge zur Chronologie der mittleren Bronzezeit im Karpatenbecken. Beiträge zur ur- und frühgeschichtlichen Archäologie des Mittelmeer-Kulturraumes 7. Bonn 1968.

P. Horálková-Enderová/A. Štrof: Pohřebiště a sídliště kultury únětické ze Slavkova u Brna, okr. Vyškov. Pravěk. Supplementum 6. Brno 2000.

B. Chropovský: Pohrebisko zo staršej doby bronzovej vo Vel'kom Grobe. In: Chropouský/Dušek/Polla 1960, 91-136.

B. Chropovský/M. Dušek/B. Polla: Pohrebiská zo staršej doby bronzovej na Slovensku I. Archaeologica Slovaca Fontes III. Bratislava 1960.

F. Innerhofer: Die mittelbronzezeitlichen Nadeln zwischen Vogesen und Karpaten. Studien zur Chronologie. Typologie und regionalen Gliederung der Hügelgräberkultur. Universitätsforschungen für prähistorische Archäologie 71, Bonn 2000.

S. Janšák: Staré osídlenie Slovenska. Dolný Hron a Ipel’ v praveku. Spisy historického odboru Matice slovenskej 3. Martin 1938.

P. Jelínek: Nálezy detských skeletov v sídliskových objektoch z neolitu, eneolitu a doby bronzovej z juhozápadného Slovenska. Študijné zvesti Aú SAV 42, 2007, 71-98.

P. Jelínek: Objekty s dvojicami ludských skeletov na sídliskách staršej a strednej doby bronzovej na Slovensku. Zborník SNM 110. Archeológia 26, 2016, 27-35. A. Knor: Zámeček v Nitranském Hrádku u Šuran na Slovensku. Archeologické rozhledy 4, 1962, 237-239, 241-250.

T. Kolník/J. Paulík: Čachtice v praveku (súpis archeologickej zbierky v Čachticiach). Študijné zvesti Aú SAV 3, 1959, 87-114.

A. Lorencová/J. Beneš/V. Podborský: Těšetice-Kyjovice 3. Únětické pohřebiště $v$ Těšeticích-Vinohradech. Brno 1987.

B. Milleker: A vattinai östelep. Temesvár 1905.

A. Mozsolics: Bronzefunde des Karpatenbeckens. Depotfundhorizonte von Hajdúsámson und Kosziderpadlás. Budapest 1967.

J.-W. Neugebauer: Fundmaterialien aus der ältesten Stufe der Hügelgräberbronzezeit aus dem Raume von Mannersdorf am Leithagebirge. Fundberichte aus Österreich 19, 1981, 157-201.

J.-W. Neugebauer/Ch. Blesl: Das Traisental in Niederösterreich. Die Siedlungserschließung einer Tallandschaft im Alpenvorland in der Bronzezeit. In: Mensch und Umwelt in der Bronzezeit Europas. Kiel 1998, 395-418.

M. Novotná: Die Äxte und Beile in der Slowakei. Prähistorische Bronzefunde IX/3. München 1970

M. Novotná: Die Nadeln in der Slowakei. Prähistorische Bronzefunde XIII/6. München 1980.

L. Olexa: Sídliská a pohrebiská z doby bronzovej v Nižnej Myšli. Archeologické rozhledy 35, 1983, 122-129.

L. Olexa: Náleziská z doby bronzovej v Nižnej Myšli. Predbežná správa o výsledkoch výskumu opevnených sídlisk a pohrebiska otomanskej kultúry. Slovenská archeológia 40, 1992, 189-204.

L. Olexa: Nižná Myšla. Osada a pohrebisko z doby bronzovej. Archeologické pamätníky Slovenska 7. Košice 2003.

J. Ondráček: Únětické pohřebiště u Rebešovic na Moravě. Sborník Československé společnosti archeologické 2, 1962, 5-100.

O: Oždáni: Výsledky záchranného výskumu v Štúrove v Obidskej puste. AVANS 1984, 1985, 182-184.

O. Oždáni: Poznámky k výskytu keramiky cudzej proveniencie na juhozápadnom Slovensku počiatkom strednej doby bronzovej. Slovenská archeológia 58, 2010, 259-272.

B. Polla: Birituálne füzesabonyské pohrebisko v Strede nad Bodrogom. In: Chropovský/Dušek/Polla 1960, 299-386.

D. Popescu: Die frühe und mittlere Bronzezeit in Siebenbürgen. București 1944

D. Popescu: Săpăturile der la Vărşand. Cercetări arheologice în Transilvania. Materiale si Cercetari Arheologice 2, 1956, 89-152.

J. Říhovský: Základy středodunajských popelnicových polí na Moravě. Studie AÚ ČSAV Brno 10. Praha 1982.

M. Stloukal: Kostry z hrobů únětické kultury ve štěrkovne v Mušově. In: Stuchlík 1987, 101-105. 
Stuchlík 1971

Stuchlík 1987

Stuchlík 1992

Stuchlík 1993

Stuchlik 2007

Točík 1964a

Točík 1964b

Točík 1978

Točík 1979

Točík $1981 a$

Točík $1981 b$

Tompa 1937

Torbrügge 1959

Vicze 2011

Vizdal 1986

Vladár 1973

Vladár 1974
S. Stuchlík: Příspěvek k poznání počátku mohylové kultury na Moravě. Archeologické rozhledy 23, 1971, 140-146.

S. Stuchlík: Únětické pohřebiště v Mušově. Studie Archeologického ústavu Československé akademie věd v Brně 14. Brno 1987.

S. Stuchlík: Die Věteřov-Gruppe und die Entstehung der Hügelgräberkultur in Mähren. Prähistorische Zeitschrift 67, 1992, 15-42.

S. Stuchlík: Středodunajská mohylová kultura. In: V. Podborský a kol. (ed.): Pravěké dějiny Moravy. Vlastivěda moravská. Země a lid. Nová řada 3. Brno 1993, 272-286.

S. Stuchlík: Pohřby v nádobách v době bronzové na Moravě. Študijné zvesti AÚ SAV 42, 2007, 197-210.

A. Točík: Die Gräberfelder der karpatenländischen Hügelgräberkultur. Fontes archaeologici pragenses 7, Praha 1964.

A. Točík: Záchranný výskum v Bajči-Vlkanove v rokoch 1959-1960. Študijné zvesti AÚ SAV 12, 1964, 5-185.

A. Točík: Staršia a stredná doba bronzová. In: Slovensko. Dejiny. Bratislava 1978, 51-79.

A. Točík: Výčapy-Opatovce a d’alšie pohrebiská zo staršej doby bronzovej na juhozápadnom Slovensku. Materialia Archaeologica Slovaca I. Nitra 1979.

A. Točík: Malé Kosihy. Osada zo staršej doby bronzovej. Materialia Archaeologica Slovaca IV. Nitra 1981.

A. Točík: Nitriansky Hrádok-Zámeček, Bez. Nové Zámky. Bronzezeitliche befestigte Siedlung der Mad'arovce-Kultur. Materialia Archaeologica Slovaca III. Nitra 1981.

F. Tompa: 25 Jahre Urgeschichtsforschung in Ungarn 1912-1936. Bericht der Römisch-Germanischen Kommission 24/25, 1937, 27-127.

W. Torbrügge: Die Bronzezeit in der Oberpfalz. Materialhefte zur bayerischen Vorgeschichte 13, Kallmünz/Opf. 1959.

M. Vicze: Bronze Age Cemetery at Dunaújváros-Duna dűlő. Dissertationes Pannonicae 4, Budapest 2011.

M. Vizdal: Výskumy a nálezy Zemplínskeho múzea v Michalovciach. AVANS 1985, 1986, 237-252.

J. Vladár: Pohrebiská zo staršej doby bronzovej v Branči. Archaeologica Slovaca. Fontes 12. Bratislava 1973.

J. Vladár: Die Dolche in der Slowakei. Prähistorische Bronzefunde VI/3. München 1974.

\title{
K nálezom zo staršej a strednej doby bronzovej z Bajča na juhozápadnom Slovensku
}

\author{
Zoja Benkovsky-Pivovarová
}

Súhrn

Príspevok sa zaoberá hrobmi s dýkami v polohe Bajč-Ragoňa II a nálezmi zo sídliska v polohe Bajč-Vlkanovo. Nálezy z obidvoch lokalít boli síce uverejnené v druhej polovici minulého storočia, zaslúžia si však viac pozornosti.

Hrob 58 z polohy Ragoňa II podla A. Točíka (1979) obsahoval dýku, ihlicu s kotúčovitou hlavicou a fragment ihlice s rúrkovite stočenou hlavicou. Podla M. Novotnej (1980) sa však v hrobe našla iba ihlica s rúrkovite stočenou hlavicou, čo zodpovedá skutočnosti (obr. 1). Podla J. Vladára (1974) patrí dýka variantu Nesvady dýk hurbanovského typu. Podla triedenia únetických dýk M. Bartelheimom (1998) zodpovedá typu N2. 1. Spol’ahlivé analógie ihlice pochádzajú napr. z hrobu 5 v Matúškove a z hrobu vo Vinodole (Benkovsky-Pivovarová/Chropovský 2015a; Novotná 1980; Točík 1979). $\mathrm{V}$ hrobe 58 bol pochovaný muž vo veku 30-40 rokov, ale na tom istom pohrebisku sa našla dýka a ihlica s rúrkovite stočenou hlavicou v hrobe 50-60 ročnej ženy (hrob 39). Ihlica má však tordovanú ihlu. Okrem toho sa v hrobe našiel aj drôtený šperk. Vzhladom na bohatý bronzový a zlatý inventár hrobu 26 s dýkou je polutovaniahodné neisté určenie pohlavia mŕtveho, ako otázny muž vo veku 20-30 rokov (Hanáková/Stloukal/Točík 1973). Kvôli nejednoznačným alebo nepublikovaným demografickým dátam nemohli byt๋ do súpisu ženských hrobov s dýkami v únetickej kultúre na Slovensku a na Morave zaradené okrem hrobu 26 z Bajča aj hrob 272 z Branča a hrob 11 z Vel'kého Grobu. Z tohto súpisu vyplýva, že dýky rôznej vel'kosti (5-18 cm) sa našli v hroboch žien vo veku 20-60 rokov. 
Objekt IX a jamy 27 aj 56, v polohe Vlkanovo, datoval A. Točík $(1964 b, 13,166)$ do stupňa B1 a považoval ich za počiatočnú fázu karpatskej mohylovej kultúry. K nálezom z 80. rokov na tej istej lokalite sa nedá zaujat’ stanovisko z dôvodov, že doposial' boli publikované iba nálezy cudzej proveniencie. Podla O. Ožd'ániho (2010) väčšina nálezov z jamy 39/82 patrí mad’arovskej kultúre.

Nálezy bronzových predmetov z objektu IX sa považujú od roku 1964 za depot, aj ked’ z nálezovej správy nevyplýva, že sa v rozmernej jame našli spolu. Takúto interpretáciu podporuje iba dláto s tulajkou, ktorého analógia pochádza z depotu v Kameníne. Ostatné bronzové predmety - dve kosákovité ihlice, závesok s koncentrickými rebrami a prsteň so špirálovitými ružicami, vyvolávajú dojem inventára hrobu ženy. Ide o bežný inventár ženských hrobov na pohrebiskách vo Svätom Petre a v Ménföcsanaku.

Nakol'ko črepy keramiky boli uverejnené väčšinou bez kresieb profilu, zaujali sme stanovisko iba k niekol'kým nálezom z uvedeného objektu. Obidva krčiažky patria mad’arovskej kultúre, pričom krčiažok s vypuklinami ešte zosilňuje dojem existencie ženského hrobu v tomto objekte. Počet krčiažkov s takouto výzdobou (Benkovsky-Pivovarová 2004) sa medzičasom rozmnožil o krčiažok z objektu 10/84 zo Štúrova, ktorý stál pri nohách 9-10 ročného dievčatka (Jelínek 2016; Ožd'áni 2010) a o krčiažok z hrobu 1060 mladistvej ženy v Ménföcsanaku (Egry 2004). Misy so zvislými uškami s otvorom nadväzujú na misy typu D1b podla A. Točíka (1981b). Mimoriadnu pozornosṫ má fragment s polkruhovitými dvojitými odtlačkami na lište (?), ktorý pripomína keramiku tzv. predmohylového horizontu v Bavorsku, v Čechách, na Morave a črep misy so zvislým lalokom na okraji. Misy tohto typu sú spomenuté pri nálezoch z jamy 56.

Predmet z kameňa, podla $A$. Točíka (1964b) pravdepodobne idol, sa dá interpretovat' skôr ako amulet. Na rôznorodost' kamenných amuletov v Karpatskej kotline upozornil I. Bóna (1975). Na Slovensku sa okrem exemplára z Bajča vyskytli tri kamenné amulety, dva pochádzajú z Nitrianskeho Hrádku (Točík 1981b) a jeden z Humenného (Vizdal 1986). K nálezu z Bajča nepoznáme žiadne analogické tvary. Z Nitrianskeho Hrádku bol zobrazený iba jeden amulet, ktorý má ten istý tvar ako amulet $\mathrm{z}$ Humenného a jeden $\mathrm{z}$ amuletov $\mathrm{z}$ Varsandu.

V bezprostrednej blízkosti objektu IX sa odkryla jama 56. Tak krčiažok, ako aj misa z tejto jamy sú typickými predstavitelmi stredodunajskej mohylovej kultúry na celom území jej rozšírenia. Typ misy D2 (Bartík 1996) sa na Morave vyskytuje už od stupňa B1 (Stuchlík 1992), typologická odlišnost’ krčiažka v porovnaní s krčiažkami karpatskej mohylovej kultúry sa výrazne prejavuje na pohrebisku v Salke I, kde sa krčiažok s vysokým hrdlom našiel iba v jednom zo 172 hrobov (Točík 1964a), preto ho treba považovat’ za import. Zlomok hornej časti ihlice s dlhým zvislým uškom z jamy 56, bohužial', neprispieva k jej datovaniu. Vzhl’adom na ihlicu s takýmto uškom a profilovanou ihlou stupňa B1 z lokality Amberg-Kleinragering sa nedá vylúčił jej datovanie už do uvedeného stupňa (Innerhofer 2000; Torbrügge 1959). Jama 27 bola od objektu IX a jamy 56 vzdialená približne $32 \mathrm{~m}$, smerom na juhovýchod. V jame sa našiel krčiažok, hrnček, dve misy, črepy d’alších nezobrazených nádob a zvieracie kosti. Bohato zdobený krčiažok sa na základe výzdoby dá paralelizovat’ s krčiažkami zo Stredy nad Bodrogom a zo sídliska II v Nižnej Myšli (Olexa 1992; 2003; Polla 1960). Krčiažkami zo Stredy nad Bodrogom sa podrobne zaoberal B. Hänsel (1968), ktorý ich datoval do svojich stupňov MD II a MD III. Misy z jamy 27 považoval $A$. Točík (1964b) za dedičstvo mad’arovskej kultúry a hrnček za spoločné dedičstvo starobronzových kultúr Zadunajska, Potisia.

V katalógu publikácie o Bajči-Vlkanove bola do strednej doby bronzovej datovaná aj jama 13, ktorou sa $A$. Točík (1964b) nezaoberal. Jama obsahovala aj zvieracie kosti a črepy siedmich nádob. Pozoruhodný je predovšetkým vysoký hrniec, zdobený plastickou páskou a ryhami. Na jeho črepoch ležali drobné, asi detské kosti a popol. Dá sa predpokladat', že tento hrniec, ktorý patrí s vel'kou pravdepodobnostou stredodunajskej mohylovej kultúre, slúžil ako pithos. Tento spôsob pochovávania je zo strednej doby bronzovej známy z lokality Olšany u Prostějova (Fojtík/Dočkalová 2007). V zozname pithoi zo Slovenska nie sú uvedené Šarovce, ktoré sa v literatúre citujú bez odovlania sa na pramene (Furmánek/Veliačik/Vladár 1991). Z tohto zoznamu vyplýva, že na juhozápadnom Slovensku sa v nádobách pochovávali väčšinou deti, a to $\mathrm{v}$ hrncoch $(1 ?, 6,7)$ alebo amforách $(4,5)$. V jednom prípade sa v tej istej nádobe našli aj fragmenty lebky dospelého indivídua (7). V jednom z hrncov bolo pochované dievča (3). Vek a pohlavie indivídua pochovaného $\mathrm{v}$ d’alšom hrnci (7) nie je známe.

Kultúrna rozmanitost’ sídliskových nálezov z Bajča dokazuje neopodstatnenost̉ ich zaradenia do počiatočnej fázy karpatskej mohylovej kultúry. Jediné nálezy, ktoré sa dajú spájat’ s mohylovou kultúrou, patria stredodunajskej facies tejto kultúry. Tá na počiatku strednej doby bronzovej pozvol’na prenikala do prostredia d’alej žijúcich starobronzových kultúr v severozápadnej časti Karpatskej kotliny. Pomenovanie tohto nálezového horizontu je závislé od publikovania a dôkladného vyhodnotenia sídliskových a hrobových nálezov stupňa B1 z územia medzi Váhom a Ipl’om.

Obr. 1. Bajč-Ragoňa II. Bronzový inventár hrobu 58, výber.

Obr. 2. Bajč-Vlkanovo. Nálezy z objektu IX, výber (podla Točík 1964b).

Obr. 3. Bajč-Vlkanovo. Nálezy z jám 13, 27 a 56, výber (podl’a Točík 1964b).

Dr. Zoja Benkovsky

Donaustr. 89/5

A - 2344 Maria Enzersdorf-Südstadt

zoja.benkovsky@gmail.com 